\title{
Correction to: Expression of miR-145 and Its Target Proteins Are Regulated by miR-29b in Differentiated Neurons
}

\author{
Abhishek Jauhari $^{1,2} \cdot$ Tanisha Singh $^{1,3} \cdot$ Sanjay Yadav ${ }^{1}$ \\ Published online: 3 July 2019 \\ (C) Springer Science+Business Media, LLC, part of Springer Nature 2019
}

\section{Correction to: Mol Neurobiol (2018) 55:8978-8990 https://doi.org/10.1007/s12035-018-1009-9}

The original version of this article unfortunately contained an error. In Fig. 8, the image under section a) NTC, and b) $\mathrm{NTC}+\mathrm{PFT} \alpha$ are copied by mistake.

The corrected Fig. 8 is hereby given below. As there is no change in values of the figure, it will not change the result of paper.

Publisher's Note Springer Nature remains neutral with regard to jurisdictional claims in published maps and institutional affiliations.

The online version of the original article can be found at https://doi.org/ 10.1007/s12035-018-1009-9

Sanjay Yadav

sanjay@iitr.res.in

Abhishek Jauhari

abhijauhari@gmail.com

Tanisha Singh

tanishasingh186@gmail.com

1 Developmental Toxicology Laboratory, Systems Toxicology and Health Risk Assessment Group, CSIR- Indian Institute of Toxicology Research (CSIR-IITR), Vishvigyan Bhawan, 31 Mahatma Gandhi Marg, Lucknow, Uttar Pradesh 226001, India

2 Academy of Scientific and Innovative Research (AcSIR), CSIRIITR Campus, New Delhi, India

3 Department of Biochemistry, School of Dental Sciences, Babu Banarasi Das University, Lucknow, Uttar Pradesh, India 

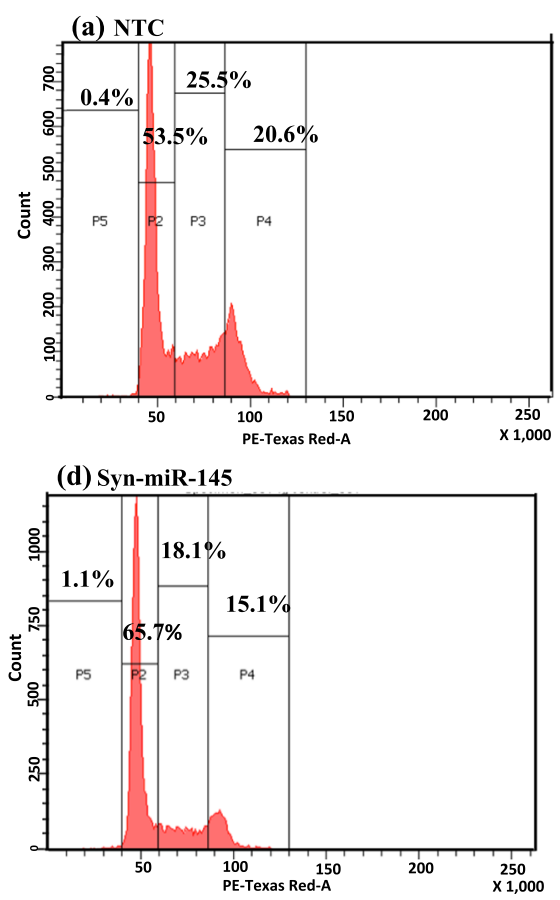

(b) NTC+PFTa

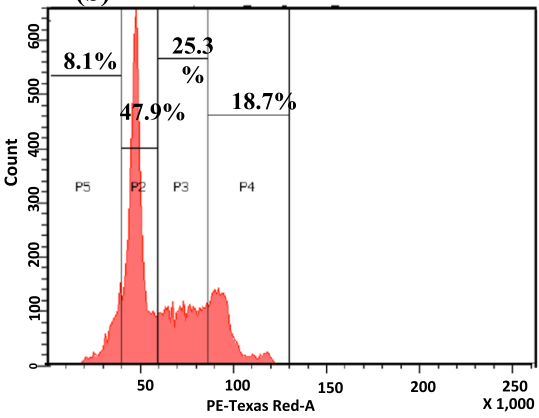

(e) Syn-miR-29+PFT $\alpha$

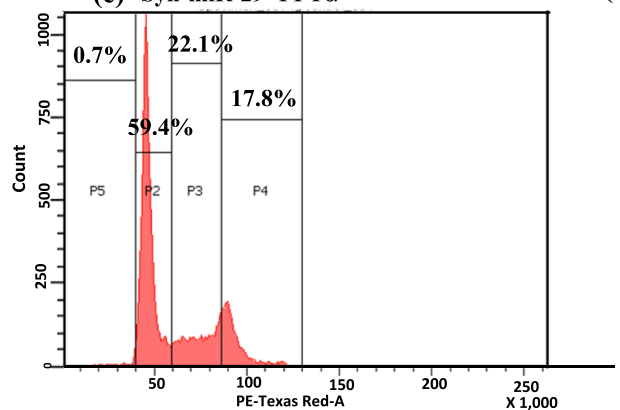

(c)Syn-miR-29b

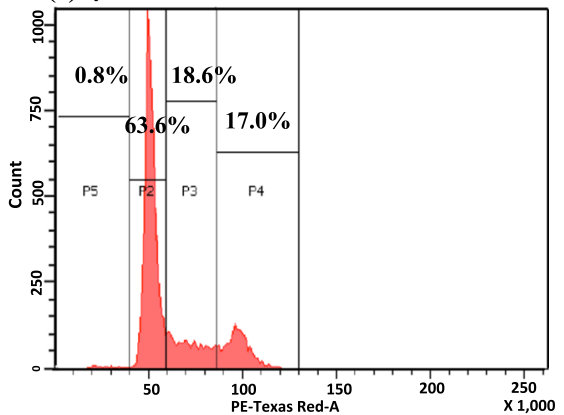

(f)

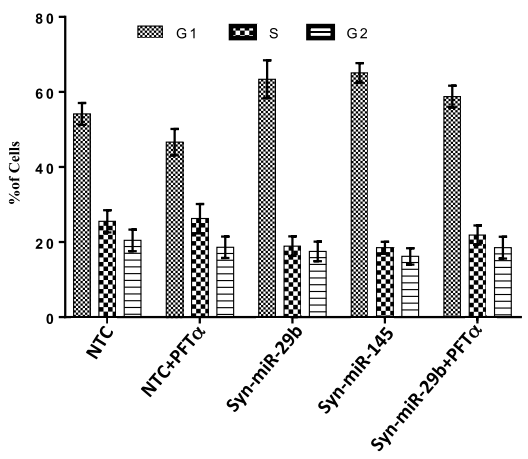

Fig. 8 Effect of overexpression of miR-145 and miR-29b on G1 phase arrest in SH-SY5Y cells. Flow cytometry-based PI uptake assay for cell cycle analysis of a SH-SY5Y cells transfected with NTC, b NTC exposed with pifithrin- $\alpha$ (PFT $\alpha$ ), $\mathbf{c}$ mimics of miR-29b (Syn-miR-29b), or d transfected with mimics of miR-145 or e transfected with mimics of
miR-29b and exposed with pifithrin- $\alpha$ (Syn-miR-29b + PFT $\alpha)$. f Bar diagram of G1, S, and G2 phase percentages of SH-SY5Y cells. All values are the mean of three individual experiments. Significant changes are calculated by Student's t test. Pifithrin- $\alpha 10 \mu \mathrm{M}$ for $24 \mathrm{~h}$ 